\title{
Analyzing the Significance of Transformational Leadership on Organizational Creativity of Employees: A Case of Insurance Companies in Jordan
}

\author{
Azzam A. Abou-Moghli ${ }^{1}$ \\ ${ }^{1}$ Department of Business Administration, Faculty of Business, Applied Science Private University, Amman, Jordan \\ Correspondence: Azzam A. Abou-Moghli, Department of Business Administration, Faculty of Business, Applied \\ Science Private University, Amman, Jordan.
}

Received: May 30, 2018

Accepted: June 19, 2018

Online Published: June 29, 2018

doi:10.5430/ijba.v9n4p64

URL: https://doi.org/10.5430/ijba.v9n4p64

\begin{abstract}
The study aims to conduct an assessment of defining qualities of a transformational leader and the role of such leaders in intellectually inspiring and intrinsically motivating the employees within their organization. The data was collected from 90 managers of 20 insurance companies and further analyzed their views pertaining to transformational leadership styles. Statistical tools were used to analyze the data. A vast majority of the respondents affirmed the significance of transformational leadership in ensuring the organizational creativity of their employees. It is concluded that the elements of transformational leadership are crucial in the development of organizational creativity of employees.
\end{abstract}

Keywords: transformational leadership, transactional leadership, organizational creativity, intellectual stimulation

\section{Introduction}

Studies pertaining to discussions of transformational or transactional leadership considered them to be full range leaderships (Gorman \& Chavez Reyes, 2018). It is important to maintain a compassionate climate within an organization, since this plays an important mediating role in adhering to organizational hierarchy, in achieving job satisfaction, and in staying committed to tasks allotted to employees by the organization (Fu \& Deshpande, 2014). Furthermore, a caring environment has a positive effect on the overall job satisfaction of employees that include their relationship with coworkers, their work performance, and their morale (Eisenberger, Malone \& Presson, 2016). In this regard, a stark difference may be noted between traditional authoritarian leaders and those that employ transformational leadership approaches.

Conversely, transformational leadership models have placed too much emphasis on the positive aspects of being a good, kind, and emphatic leader that brings about major changes in the performance of employees. These models have ignored some of the negative effects of being a charismatic and kind-hearted leader. In a study conducted by Eisenbeib \& Boerner (2013), the participants disclosed that though good transformational leadership strategy promoted and encouraged followers' creativity; it also stimulated an increase in employee dependency, which consequently had a negative impact on their creativity and confidence. Therefore, a delicate balance must be maintained, when strategizing key characteristics of effective transformational leadership skills.

It was seen that there is a limitation with regard to existing studies pertaining to the significance of transformational leadership styles. Such studies have merely discussed the effects of utilizing this leadership style on the innovative growth of organizations as opposed to address the creative growth of employees. The study aims to fill this gap and contribute to existing research by addressing the effects of transformational leadership on the creative growth of employees. Therefore, this study has conducted an analysis of the characteristics that make an individual a transformational leader. It additionally examined the significance of leaders and their impact on the performance and general wellbeing of their employees. Furthermore, the relationship between transformational leaders and their staff in attaining organizational goals was evaluated. In addition to these elements, the study examined intellectual stimulation provided by transformational leaders to their employees to achieve common goals. In order to conduct this investigation, an analysis was conducted of 20 insurance companies in Jordan. It is to be noted that the nature of the insurance industry in particular demands the need for transformational leaders, who are experts at raising the 
morale of the workers by keeping them motivated and optimistic in the thankless and unappreciative atmosphere of the insurance industry.

\section{Literature Review}

Recent studies have highlighted the effectiveness of transformational leadership styles in promoting the development of an organization (Engelen et al., 2015). Additional studies have discussed that this style of leadership relies on the harmonious working of leaders and followers to improve their levels of motivation and drive (Gilbert, Horsman \& Kelloway, 2016). A stark difference may be noted between such leadership styles and those that adopt a transactional approach, where contractual exchanges between subordinates are seen (Hamstra et al., 2014). Conversely, transformational leadership styles eschew the use of contractual exchanges and instead rely on maintaining a beneficial social relationship with subordinates (Nanjundeswaraswamy \& Swamy, 2014). Furthermore, transformational leadership is usually associated with the inspirational motivation, idealized influence, intellectual stimulation and inspirational motivation.

These two leadership styles influence employees' and organizational outcomes in different ways. For instance, studies have highlighted that the utilization of transformational leadership styles has an immensely positive influence on the level of commitment within the organization (Top, Akdere \& Tarcan, 2015), job satisfaction (Choi et al., 2016) and employee's performance (Caillier, 2014). However, transactional leadership impact was found to be of lesser degree as compared to transformational leadership in terms of outcomes from employee's end (McCleskey, 2014). These studies elaborated that transactional leaders carry out group interventions only under the conditions of absolute necessity and may rely on issuing disciplinary threats to assure the performance of their employees. Such management techniques proved to be extremely detrimental to the creative growth of an employee over the long run. These may be contrasted with transformational management techniques, whereby the overall goal is to conduct a transformation with regard to the personal ideologies and values of the employees and enable them to move into more evolved levels of aspirations (Caniëls, Semeijn \& Renders, 2018) through the utilization of idealized influence, intellectual stimulation, individualized consideration, and inspirational motivation.

Within the context of this study, it is essential to define creativity and its strong association with a transformational style of leadership. In this regard, studies discuss that creativity stands as a representation of valuable and innovative idea generation (Amabile \& Pratt, 2016). The utilization of creativity within corporate organizations was noted by studies, which indicated that the evolution of modern industries had strongly led to a need for innovations in this context (Anderson, Potočnik \& Zhou, 2014). It was corroborated in further research that discussed the importance of innovation through creativity with regard to elevating the success and competitive advantage of an organization (Fraj, Matute \& Melero, 2015). Additionally, a firm's ability to accept challenges was considered to be an integral factor in determining its success (Eragula, 2015). Creativity in this regard, pertains to the ability of an individual to produce novel ideas in order to lead the organization towards innovative growth. It is therefore of great importance that the styles of leadership that govern the working operations of an organization undergo an evolution in terms of utilizing the creativity of their employees. Such an evolution will effectively pave the way for innovative growth and development within the company.

Therefore, the applicability of transformational leadership styles in enabling organizational development through innovation may be seen (Nijstad, Berger-Selman \& De Dreu, 2014). Causal factors may be attributed to the feelings of respect, trust and loyalty experienced by the followers of transformational leaders, due to which they are motivated and inspired to perform to the best of their abilities (Dvir et al., 2015). The effectiveness of transformational leadership in inspiring their employees to increase their performative standards and develop creative solutions to problems was discussed in various studies pertaining to this discussion (Bass, 1985; Yammarino \& Bass, 1990). This was corroborated by further research that the utilization of transformational leadership leads to the elevation of satisfaction among employees (Men, 2014).

As discussed earlier in this review, idealized influence, intellectual stimulation, individualized consideration and inspirational motivation are the four constituents of transformational leadership (McCleskey, 2014). Idealized influence is a key element of the transformational process, whereby the employees are influenced by the leader's charismatic leadership. This inspiration aids them in developing creative solutions to problems, which smoothens the trouble-shooting process (Gorman \& Gamble, 2016). Studies discussed that individualized consideration revolves around the transformational leaders assuming positions of employee mentorship (Kossek et al., 2018). Furthermore, inspirational motivation was described as a type of transformational leadership, where leaders effectively communicate a prospective idealized version of the organization that is to be emulated by the employees (Gilbert, Horsman \& Kelloway, 2016). Lastly, intellectual stimulation is described as a process where transformational leaders 
stimulate and motivate their employees to develop novel approaches and innovative solutions to old and familiar problems (Herman \& Chiu, 2014). Thus, it was seen that the use of a transformative approach in organizational leadership is highly effective in the innovative growth of the employees affiliated with the organization under consideration. The ability of transformational leadership in enabling employees to develop creative solutions to previous problems faced by the organization has been widely lauded in existing research. It was further discussed that this creative growth and development of the employees greatly contributes to a high degree of innovative organizational development.

\section{Methodology}

This study has employed the use of a quantitative study to investigate the effects of transformational leadership on the organizational creativity of employees. Data from the employees of insurance companies in Jordan was collected through a questionnaire. Insurance companies in particular are noted for their high-pressure and unwelcoming environment and were selected for this reason. The participants were 90 managers from 20 insurance companies in Jordan. Additional specifications were made with regard to these participants, whereby the study only incorporated the participation managers that fell within the age range of 35-50 years. Moreover, these managers were required to have prior work experience equal to or greater than 5 years. Additionally, they were chosen on the basis of their leadership positions, such that managers assuming higher leadership roles were selected for the study. The questionnaire pertained to addressing the behavioral attitudes of these managers under difficult situations, which are faced by their employees under consideration. Additional questions that were asked in the questionnaire were framed to test the managers' existing conceptual knowledge of transformational leadership. The data that was collected from the employees through this questionnaire was then analyzed via the use of descriptive and inferential statistics and tabulated for clarity.

\section{Results}

The managers of 20 Jordanian insurance companies were recruited for this study and classified according to age, gender and work-experience. Based on gender, it was seen that there was a significantly greater number of male employees as compared to female ones, where the former formed $62.2 \%$ of the sample population and the latter formed the remaining $37.8 \%$. 12.2\% of these recruited employees were aged between 35 to 40 years of age, 53.3\% were between 40 to 45 years and lastly, $34.4 \%$ of the employees were between 45 to 50 years of age. Furthermore, $12.2 \%$ of the employees had work experience ranging between 5-7 years. Additionally, $44.4 \%$ of the employees had work experience between 7-9 years. Lastly, $43.3 \%$ of the employees had between 9 to 11 years of work experience (Table 1).

Table 1. Demographics

\begin{tabular}{lll}
\hline & $\mathrm{N}$ & $\%$ \\
\hline Gender & & \\
$\quad$ Male & 56 & 62.2 \\
$\quad$ Female & 34 & 37.8 \\
Age & & \\
$\quad$ 35-40 years & 11 & 12.2 \\
40-45 years & 48 & 53.3 \\
$\quad$ 45-50 years & 31 & 34.4 \\
Experience & & \\
5-7 years & 11 & 12.2 \\
7-9 years & 40 & 44.4 \\
9-11 years & 39 & 43.3 \\
\hline
\end{tabular}

A questionnaire-based approach was employed in order to investigate these managers. In this regard, a 5-point Likert scale (1-Strongly Disagree, 5-Strongly Agree) was used in order to grade the responses of the participants. The responses were quantitatively assessed in percentages. The questionnaire included six statements that were used to obtain the perceptions of the managers regarding transformational leadership and its effectiveness. The statements aimed to investigate the behavioral responses of these participants for a range of different situations. Furthermore, the awareness of these managers regarding the significance of transformational leadership was investigated.

The first statement addressed the use of disciplinary tactics as a means to ensure the overall performance and efficiency of the employees. As indicated by the results, a significant majority of the respondents (75.5\%) did not 
agree with using such disciplinary tactics in order to ensure good employee performance. Furthermore, no respondent agreed to the use of disciplinary measures as a means to ensure performance (Table 2).

Table 2. Disciplining employees is the best way to ensure the quality of their work and overall performance

\begin{tabular}{llllll}
\hline & & Frequency & Percent & Valid Percent & Cumulative Percent \\
\hline Valid & Strongly Disagree & 31 & 34.4 & 34.4 & 34.4 \\
& Disagree & 37 & 41.1 & 41.1 & 75.6 \\
Neutral & 22 & 24.4 & 24.4 & 100.0 \\
& Total & 90 & 100.0 & 100.0 & \\
\hline
\end{tabular}

The second statement aimed to investigate the perceptions of the respondents regarding the penalization of employees with consistently poor working performance. An overwhelming majority of the respondents $(82.2 \%)$ disagreed to the use of penalizations for amending poor work performance. Nevertheless, a small minority (2.2\%) did agree to the use of penalizations (Table 3).

Table 3. Employees consistently demonstrating poor work performance need to be penalized through salary cuts so that they work more diligently next time

\begin{tabular}{llllll}
\hline & Frequency & Percent & Valid Percent & Cumulative Percent \\
\hline Valid & Strongly Disagree & 40 & 44.4 & 44.4 & 44.4 \\
& Disagree & 34 & 37.8 & 37.8 & 82.2 \\
& Neutral & 14 & 15.6 & 15.6 & 97.8 \\
& Agree & 2 & 2.2 & 2.2 & 100.0 \\
& Total & 90 & 100.0 & 100.0 & \\
\hline
\end{tabular}

The third statement investigated the effectiveness of inspiring employees to enable them to reach innovative solutions to pre-existing problems. In this regard, a vast majority of the respondents (80\%) agreed that motivating employees was a good way to ensure them to deliver creativity in their solutions. Nevertheless, a small minority $(3.3 \%)$ disagreed regarding the significance of employee motivation (Table 4).

Table 4. It is very important to inspire and motivate employees so that they deliver more creative solutions to existing problems

\begin{tabular}{llllll}
\hline & Frequency & Percent & Valid Percent & Cumulative Percent \\
\hline Valid & Disagree & 3 & 3.3 & 3.3 & 3.3 \\
& Neutral & 15 & 16.7 & 16.7 & 20.0 \\
& Agree & 33 & 36.7 & 36.7 & 56.7 \\
& Strongly Agree & 39 & 43.3 & 43.3 & 100.0 \\
& Total & 90 & 100.0 & 100.0 & \\
\hline
\end{tabular}

The fourth statement assessed the perceptions of the respondents regarding the applicability of transformational leadership styles over transactional ones in any organizational setting. $67.7 \%$ of the respondents agreed that transformational leadership styles were more useful, which additionally indicated their awareness and conceptual knowledge in this regard (Table 5).

Table 5. Transformational leadership styles need to be implemented rather than transactional leadership styles within any organization

\begin{tabular}{llllll}
\hline & & Frequency & Percent & Valid Percent & Cumulative Percent \\
\hline Valid & Neutral & 29 & 32.2 & 32.2 & 32.2 \\
& Agree & 31 & 34.4 & 34.4 & 66.7 \\
& Strongly Agree & 30 & 33.3 & 33.3 & 100.0 \\
& Total & 90 & 100.0 & 100.0 & \\
\hline
\end{tabular}


In the fifth statement, the effectiveness of terminating employees who were creatively demotivated under high-pressure work situations was addressed. The statement addressed the significance of employee termination as a means to ensure the organization's continued and uninterrupted innovative development. A vast majority of the respondents $(91.1 \%)$ disagreed regarding the effectiveness of employee termination in this regard. Additionally, no participants agreed regarding the effectiveness of this technique (Table 6).

Table 6. Employees who are creatively demotivated under high-pressure situations need to be terminated so that the innovative growth of the organization is not compromised

\begin{tabular}{llllll}
\hline & Frequency & Percent & Valid Percent & Cumulative Percent \\
\hline Valid & Strongly Disagree & 63 & 70.0 & 70.0 & 70.0 \\
& Disagree & 19 & 21.1 & 21.1 & 91.1 \\
& Neutral & 8 & 8.9 & 8.9 & 100.0 \\
& Total & 90 & 100.0 & 100.0 & \\
\hline
\end{tabular}

The last statement aimed to investigate the perceptions of the respondents regarding the key attributes of a good manager. In this regard, the statement addressed that the ability to creatively transform employees was the factor of differentiation between good and bad managers. A vast majority of the respondents (63.3\%) affirmed this to be the factor of differentiation between good and bad managers. Nevertheless, a small minority of the respondents (12.2\%) did not give weightage to creatively transforming employees (Table 7).

Table 7. A good manager is differentiated through his or her ability to transform employees into individuals with a highly developed sense of organizational creativity

\begin{tabular}{llllll}
\hline & Frequency & Percent & Valid Percent & Cumulative Percent \\
\hline Valid & Strongly Disagree & 2 & 2.2 & 2.2 & 2.2 \\
& Disagree & 9 & 10.0 & 10.0 & 12.2 \\
& Neutral & 22 & 24.4 & 24.4 & 36.7 \\
& Agree & 38 & 42.2 & 42.2 & 78.9 \\
& Strongly Agree & 19 & 21.1 & 21.1 & 100.0 \\
& Total & 90 & 100.0 & 100.0 & \\
\hline
\end{tabular}

Table 8. Impact of Transformational Leadership on Employee Motivation

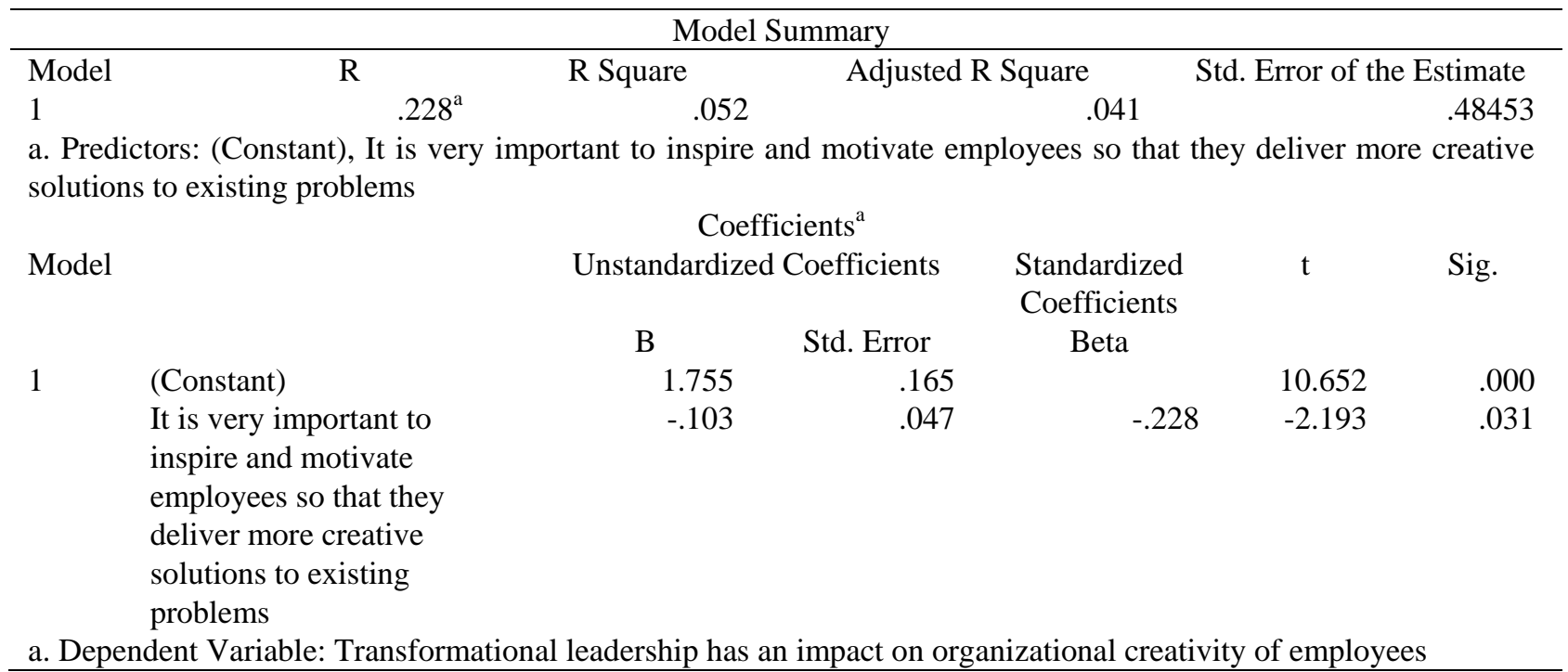

As may be seen, transformational leadership plays a vital role in boosting employee motivation and development (p-value $0.031 ; 5 \%$ significance level). 
Table 9. Impact of transformational leadership on employees transformation and growth

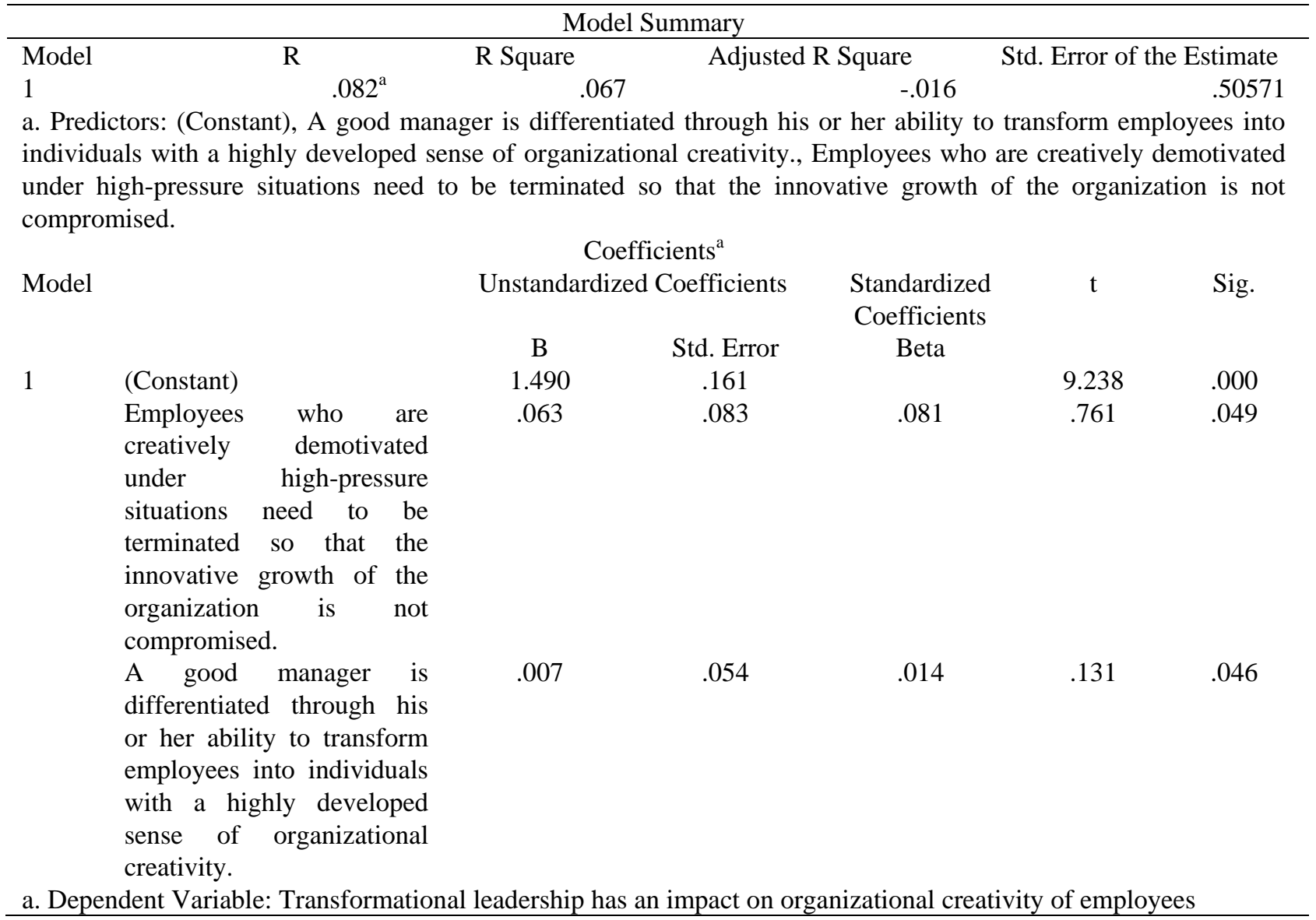

The results demonstrate the importance of transformational leadership in influencing an organization's innovative development, where the p-value was 0.049 and depicted a significance of 5\%. Additionally, the results of table 9 indicate the effectives of such leadership styles in enabling employee development, transformation and creativity, as evidenced by the p-value of 0.046 and significance of $5 \%$ (Table 9).

\section{Discussion}

This study conducted an analysis of the characteristics defining a transformational leader and the significance of such leaders in ensuring the performative attitudes and overall wellbeing of their employees. This study further aimed to assess the working relationship between such transformational leaders and their employees and how this relationship assisted in the attainment of organizational goals. Furthermore, the study has aimed to examine how transformational leaders intellectually stimulated their employees in order to perform to the best of their abilities and achieve a common goal. Therefore, this study assessed the relevance of transformational leadership in the organizational creativity of employees within the corporate sector. It was seen that the results obtained within this study were strongly in line with existing research on the significance of transformational leadership in organizational spheres.

In order to carry out this analysis, an investigation was conducted of 20 insurance companies in Jordan. The managers of those organizations were addressed via a questionnaire-based approach. This helped to gain an understanding of their views pertaining to transformational leadership styles and its relevance in the organizational sphere today. It was seen that an overwhelming majority of the participants agreed with statements that expressed the importance of utilizing transformational styles of leadership as compared to transactional styles of leadership. Furthermore, these participants expressed disagreement with statements that considered the use of disciplinary threats as a vital factor in the assurance of employee work quality. Furthermore, an overwhelming majority of the key respondents agreed that good managers are differentiated through their ability to inspire their employees and stimulate them intellectually in order to deliver more innovative work output. These results were in line with 
expectations pertaining to the usefulness of implementing a transformational style of leadership as discussed in the literature review.

Previous literature conducted with regard to transformational leadership discussed its positive attributes of inspiring feelings of loyalty and admiration among employees (Mittal \& Dhar, 2015; Kehr, Amann \& Giessner, 2016). These studies highlighted that transformational leadership is built on concepts of intellectual stimulation and intrinsic motivation. These core concepts of transformational leadership were addressed in the questionnaire-based investigation conducted within this study. A vast majority of the participants agreed that it was extremely crucial to a company's innovative growth to intellectually stimulate and intrinsically motivate their employees. This research was therefore strongly in line with existing research conducted with this regard. Furthermore, the literature review discussed the disadvantages of utilizing disciplinary threats in order to regulate the work performance of their employees (Cascio, 2018). It was discussed that such a leadership approach only served the purpose of further demotivating their employees and reducing creative work output. An overwhelming majority of the managers considered the use of such disciplinary threats as unhelpful tactics in the promulgation of creativity within their employees. Furthermore, existing literature targeted the significance of employing transformational leadership styles as compared to transactional leadership styles. It was discussed that transactional leadership styles were not useful in elevating the creativity of the employees of any organization and would prove disadvantageous over the long run (Khan, 2017). The results therefore, displayed that these participants had sufficient conceptual knowledge pertaining to transformational leadership styles. Furthermore, these participants agreed that the ability to intellectually inspire and intrinsically motivate their employees was a vital factor in the differentiation between good and bad leaders. It was therefore seen that this research was strongly in line with existing research conducted with this regard (Kauppila, 2018).

\section{Conclusion}

This study has aimed to conduct an assessment of the defining qualities of a transformational leader and the significance of such leaders in intellectually inspiring and intrinsically motivating the employees within their organization. It was seen that an overwhelming majority of those managers considered the intellectual stimulation and creative growth of their employees to be an important factor in the innovate growth and development of their organization over the long term. Moreover, these managers considered the use of disciplinary threats as highly detrimental to the creative growth of their employees. It was; therefore, seen that this research strongly corroborated existing research conducted with regard to demonstrate the significance of transformational leadership styles in the corporate sector today. However, there are cases, where employees work well, but the management is weak that results in poor workplace performance. At times, it is important to encourage and inspire employees so that they produce good quality of work. Moreover, it is also important to avoid demotivating employees to a point where they are no longer willing to perform well, so that the innovative growth is not compromised by any means. For future reference; it is recommended to assess behavior of these leadership and how they impact different areas of an organization to ensure competitiveness of an organization and creativity of employees.

\section{References}

Amabile, T.M., \& Pratt, M.G. (2016). The dynamic componential model of creativity and innovation in organizations: Making progress, making meaning. Research in Organizational Behavior, 36, 157-183. https://doi.org/10.1016/j.riob.2016.10.001

Anderson, N., Potočnik, K., \& Zhou, J. (2014). Innovation and creativity in organizations: A state-of-the-science review, prospective commentary, and guiding framework. Journal of Management, 40(5), 1297-1333. https://doi.org/10.1177/0149206314527128

Caillier, J.G. (2014). Toward a better understanding of the relationship between transformational leadership, public service motivation, mission valence, and employee performance: A preliminary study. Public Personnel Management, 43(2), 218-239. https://doi.org/10.1177/0091026014528478

Caniëls, M.C., Semeijn, J.H., \& Renders, I.H. (2018). Mind the mindset! The interaction of proactive personality, transformational leadership and growth mindset for engagement at work. Career Development International, 23(1), 48-66. https://doi.org/10.1108/CDI-11-2016-0194

Cascio, W. (2018). Managing human resources. McGraw-Hill Education.

Choi, S.L., Goh, C.F., Adam, M.B.H., \& Tan, O.K. (2016). Transformational leadership, empowerment, and job satisfaction: the mediating role of employee empowerment. Human Resources for Health, 14(1), 73. https://doi.org/10.1186/s12960-016-0171-2 
Dvir, T., Eden, D., Avolio, B.J., \& Shamir, B. (2015). The impact of Transformational Leadership.

Eisenbeib, S.A., \& Boerner, S. (2013). A double - edged sword: Transformational leadership and individual creativity. British Journal of Management, 24(1), 54-68. https://doi.org/10.1111/j.1467-8551.2011.00786.x

Eisenberger, R., Malone, G.P., \& Presson, W.D. (2016). Optimizing perceived organizational support to enhance employee engagement. Society for Human Resource Management and Society for Industrial and Organizational Psychology.

Engelen, A., Gupta, V., Strenger, L., \& Brettel, M. (2015). Entrepreneurial orientation, firm performance, and the moderating role of transformational leadership behaviors. Journal of Management, 41(4), 1069-1097. https://doi.org/10.1177/0149206312455244

Eragula, R. (2015). Confidence in Leadership. Advances in Economics and Business Management, 2(11), $1070-1072$.

Fraj, E., Matute, J., \& Melero, I. (2015). Environmental strategies and organizational competitiveness in the hotel industry: The role of learning and innovation as determinants of environmental success. Tourism Management, 46, 30-42. https://doi.org/10.1016/j.tourman.2014.05.009

Fu, W., \& Deshpande, S.P. (2014). The impact of caring climate, job satisfaction, and organizational commitment on job performance of employees in a China's insurance company. Journal of Business Ethics, 124(2), 339-349. https://doi.org/10.1007/s10551-013-1876-y

Gilbert, S., Horsman, P., \& Kelloway, E.K. (2016). The Motivation for Transformational Leadership Scale: An examination of the factor structure and initial tests. Leadership \& Organization Development Journal, 37(2), 158-180. https://doi.org/10.1108/LODJ-05-2014-0086

Gorman, C.A., \& Chavez Reyes, D. (2018). Full Range Focus: How Regulatory Focus Influences the Relationship between Leader Behavior and Subordinate Outcomes. ARBS 2018 PROCEEDINGS, 1, 36.

Gorman, C.A., \& Gamble, J. (2016). Leader behavior and follower work behavior: the influence of follower characteristics.

Hamstra, M.R., Van Yperen, N.W., Wisse, B., \& Sassenberg, K. (2014). Transformational and transactional leadership and followers' achievement goals. Journal of Business and Psychology, 29(3), 413-425. https://doi.org/10.1007/s10869-013-9322-9

Herman, H.M., \& Chiu, W.C. (2014). Transformational leadership and job performance: A social identity perspective. Journal of Business Research, 67(1), 2827-2835. https://doi.org/10.1016/j.jbusres.2012.07.018

Kauppila, O.P. (2018). How does it feel and how does it look? The role of employee motivation in organizational learning type. Journal of Organizational Behavior. https://doi.org/10.1002/job.2270

Kehr, H.M., Amann, D.G., \& Giessner, S. (2016). Transformational leadership meets follower motives: Compatibility of dimensions of transformational leadership and follower motives determines work-related outcomes. Potsdam Leadership Symposium, Potsdam, Germany.

Khan, N. (2017). Adaptive or transactional leadership in current higher education: A brief comparison. The International Review of Research in Open and Distributed Learning, 18(3). https://doi.org/10.19173/irrodl.v18i3.3294

Kossek, E.E., Petty, R.J., Bodner, T.E., Perrigino, M.B., Hammer, L.B., Yragui, N.L., \& Michel, J.S. (2018). Lasting Impression: Transformational Leadership and Family Supportive Supervision as Resources for Well-Being and Performance. Occupational Health Science, 1-24. https://doi.org/10.1007/s41542-018-0012-X

McCleskey, J.A. (2014). Situational, transformational, and transactional leadership and leadership development. Journal of Business Studies Quarterly, 5(4), 117.

Men, L.R. (2014). Strategic internal communication: Transformational leadership, communication channels, and employee satisfaction. Management Communication Quarterly, 28(2), 264-284. https://doi.org/10.1177/0893318914524536

Mittal, S., \& Dhar, R.L. (2015). Transformational leadership and employee creativity: mediating role of creative self-efficacy and moderating role of knowledge sharing. Management Decision, 53(5), 894-910. https://doi.org/10.1108/MD-07-2014-0464

Nanjundeswaraswamy, T.S., \& Swamy, D.R. (2014). Leadership styles. Advances in Management, 7(2), 57. 
Nijstad, B.A., Berger-Selman, F., \& De Dreu, C.K. (2014). Innovation in top management teams: Minority dissent, transformational leadership, and radical innovations. European Journal of Work and Organizational Psychology, 23(2), 310-322. https://doi.org/10.1080/1359432X.2012.734038

Top, M., Akdere, M., \& Tarcan, M. (2015). Examining transformational leadership, job satisfaction, organizational commitment and organizational trust in Turkish hospitals: public servants versus private sector employees. The International Journal of Human Resource Management, 26(9), 1259-1282. https://doi.org/10.1080/09585192.2014.939987 